\title{
A RESTORATION ORIENTED HBIM SYSTEM FOR CULTURAL HERITAGE DOCUMENTATION: THE CASE STUDY OF PARMA CATHEDRAL
}

\author{
N. Bruno, R. Roncella \\ Università degli Studi di Parma, Dipartimento di Ingegneria e Architettura, Parco Area delle Scienze 181A, 43124, Parma, Italy - \\ nazarena.bruno@studenti.unipr.it, riccardo.roncella@unipr.it
}

Commission II, WG II/8

KEY WORDS: HBIM, Cultural Heritage, Survey, Metadata, 3D Modelling

\begin{abstract}
:
The need to safeguard and preserve Cultural Heritage $(\mathrm{CH})$ is increasing and especially in Italy, where the amount of historical buildings is considerable, having efficient and standardized processes of $\mathrm{CH}$ management and conservation becomes strategic. At the time being, there are no tools capable of fulfilling all the specific functions required by Cultural Heritage documentation and, due to the complexity of historical assets, there are no solution as flexible and customizable as $\mathrm{CH}$ specific needs require. Nevertheless, BIM methodology can represent the most effective solution, on condition that proper methodologies, tools and functions are made available. The paper describes an ongoing research on the implementation of a Historical BIM system for the Parma cathedral, aimed at the maintenance, conservation and restoration.

Its main goal was to give a concrete answer to the lack of specific tools required by Cultural Heritage documentation: organized and coordinated storage and management of historical data, easy analysis and query, time management, 3D modelling of irregular shapes, flexibility, user-friendliness, etc.

The paper will describe the project and the implemented methodology, focusing mainly on survey and modelling phases. In describing the methodology, critical issues about the creation of a HBIM will be highlighted, trying to outline a workflow applicable also in other similar contexts.
\end{abstract}

\section{INTRODUCTION}

In recent years, the need to safeguard and preserve Cultural Heritage $(\mathrm{CH})$ is increasing and it should represent a large investment field with returns in economic growth, employment and social cohesion. Especially in Italy, where the amount of historical buildings is considerable, having efficient and standardized processes of $\mathrm{CH}$ management and conservation becomes strategic.

At the time being, there are no tools capable of fulfilling all the specific functions required by Cultural Heritage documentation and, due to the complexity of historical assets, there are no solution as flexible and customizable as $\mathrm{CH}$ specific needs require. Processes are still scarcely digitized and several activities require complex management, which is hardly addressable with traditional methods. On the other hand, the lack of easy-to-use tools, tailored for $\mathrm{CH}$ management, and the scepticism of operators, limit the adoption of new techniques (such as BIM (Building Information Modelling) processes) leading to prefer the use of traditional and consolidated methodologies. Nevertheless, applying BIM methodology in this context can lead to process standardisation and greater efficiency.

BIM methodology, providing an information system at architectural scale and making possible to manage semantically enriched three-dimensional models (Saygi et al., 2013) can represent the most effective solution, on condition that proper methodologies, tools and functions are made available.

Currently, BIM is principally associated to new construction works and only in the last years its use is spreading to existing buildings too (Volk et al., 2014), while in the field of cultural heritage documentation BIM is seldom applied.

Lack of public and government investments in this direction and the many still enduring difficulties (starting from surveyed data, modelling difficulties, irregularities etc.) make studies about HBIM still few and prerogative of universities and research institutes (De Luca et al., 2011; Fassi et al., 2015; Dore et al., 2015)

Nevertheless, BIM should represent the most natural and modern approach to historical assets management, providing many advantages such as documentation over time, management of different construction phases (Stefani et al., 2010), support for structural analysis (Dore et al., 2015; Crespi et al., 2015), unique database for all data about the building (Fai et al., 2011), support for ordinary maintenance programs (Fassi et al., 2015), support for Augmented Reality applications and web sharing (Fassi et al., 2015) and so on.

In the international panorama (Volk et al., 2014; Fassi et al., 2015), the use of BIM for CH applications, has low diffusion, mainly due to the difficulties in its implementation. Problems arise w.r.t. geometric modelling, especially of irregularities that do not fit well with the parametric modelling typical of BIM (Eastman et al., 2008; Garagnani et al., 2013). At the same time, information organization pays the lack of as flexible and customizable solution as required by the heterogeneous and difficult to standardize structure of historical data.

Another non-trivial aspect is the multi-temporality of information and the need to have a system usable for diachronic analyses. Historical data are, in fact, by their nature multitemporal and, in addition, conservation is a continuous activity that requires constant updating of information and continuous collection and processing of different data.

Last but not least, an interdisciplinary approach is mandatory to well know the building and translate it correctly in a virtual model. The operators who work in Cultural Heritage field are not used to work with databases, information systems, 3D models etc., so a system tailored for $\mathrm{CH}$ management should be 
user-friendly and easy to use/learn even for non-experts (Fassi et al., 2015).

The paper describes an ongoing research on the implementation of a Historical BIM system for the Parma cathedral, aimed at the maintenance, conservation and restoration (Bruno, 2018). Its main goal was to give a concrete answer to the lack of specific tools required by Cultural Heritage documentation: organized and coordinated storage and management of historical data, easy analysis and query, time management, 3D modelling of irregular shapes, flexibility, user-friendliness, etc. The application developed in this work started from a BIM system and enriched it with functions to address these goals. In particular, a specifically designed database was implemented, where all data about the historical building can be stored. A tailored database is necessary to organize historical data that generally are not standardized, have a complex structure and are fuzzy in their description. The database is compliant to the currently in-force Italian regulations and allows storing and retrieving information useful for maintenance purposes.

The application was implemented with the specific aim of providing tools also for non- AEC experts: it gives user-friendly graphical interfaces to access the data and makes available tools for data entry, element modelling, attribute query and thematic mapping.

It can be integrated into the main commercial BIM software (at the moment the experimentation has been limited to Autodesk Revit (Autodesk, 2018)) or accessed via web. One of the main goals was not to be bounded to a specific software and to make the system usable on a larger scale, by developing a flexible and customizable methodology that can be applied to a wide range of historical assets.

In this paper the Cathedral of Parma was chosen as case study, but the implemented methodology can be applied to other similar historical buildings.

\section{METHODOLOGY}

To correctly document cultural heritage buildings, a preliminary phase of study, in which building characteristics are assessed, is crucial. Both geometrical survey and in-depth historical and archival research have to be performed since historical data are essential to have the basic knowledge of the building past.

The first phase of the work presented here involved the analysis of the regulatory requirements and specific needs that the Parma Cathedral presents.

Then, the HBIM implementation has been conceived as an

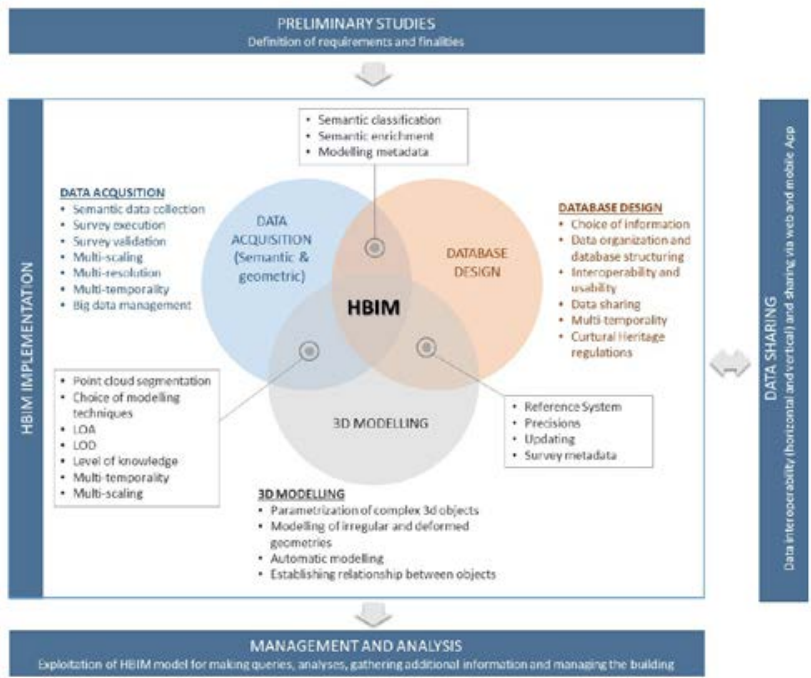

Figure 1_Methodology overview. integrated process of survey \& data acquisition, 3D modelling and database design \& data entry (Figure 1).

Especially in the cultural heritage field, the creation of a BIM is not a linear process, but an integrated and circular one. Survey, modelling and database design influence each other. For example, the accuracy with which the survey is performed and the achieved level of knowledge of the object influence the quality of the model (in terms of accuracy and adherence to reality) and of the database (in terms of organization of information and data stored).

For this reason, designing these components independently leads to inconsistencies and reduces the effectiveness of the global system.

Today there are different consolidated techniques available in each of these fields, but in order to analyse historical assets, not all the methodologies are suitable. In the work, all the three issues have been addressed, in order to define a complete methodology, but in this paper, the focus is mainly on survey and modelling phases.

As far as geometric survey and data elaboration are concerned, although they are very investigated topics (Castagnetti et al., 2017; Fassi et al., 2010; Remondino, 2011) and, to date, the acquisition workflow is well-established, no specific references are about the integration of these acquired data in a BIM environment, nor about their exploitation to certify the quality of the BIM model.

Likewise, 3D modelling techniques and commercial software that can be used to represent a building are well-known and discussed by literature (Achille et al., 2007; Guidi et al., 2009). As for the survey, even for modelling, it is not yet adequately defined how certify and validate BIM model quality and accuracy, which are influenced by the quality of the data surveyed and the modelling operations carried out.

\section{THE CASE STUDY: PARMA CATHEDRAL}

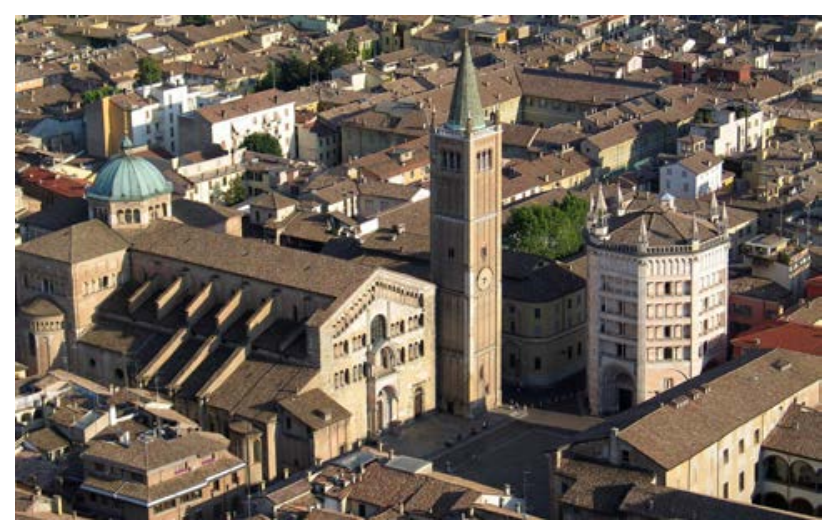

Figure 2_The Parma Cathedral. From: www.up.aci.it

Parma Cathedral was constructed from the second half of the XI century and, during its lifetime, it has been subject to changes, additions, damages and repair works.

At present, the plan of the cathedral is based on a Latin cross with three naves, composed by seven bays. Both the nave and the aisles are covered by a cross vault system while the gallery has barrel vaults. The cross section of the structure is completed by the lateral chapels, built during the XVI century.

The transept and the choir rise up to the nave. The transept has five domed aisles and the crossing is covered by a dome that rises on an octagonal tambour. Particularly interesting is the crypt, which is built under the transept and the choir. Externally, the cathedral is chiefly built of bricks, although, as evidenced by some plaster remains, it had to be entirely 
plastered. Lesenes and corners are instead made of stone, especially sandstone and limestone, while the embellishments have various materials including terracotta and marble.

The works on the cathedral have occurred since XVI century and last today. At present, the main problems relate to the structural asset and to the material decay. As far as the former is concerned, they are principally due to the high thrusts of the vaults of the central nave and the weight of the dome, which cause a considerable out-of-plumb in the side walls and the subsidence of the structures under the dome. Material decay is instead due to the presence of limestone or sandstone in the external masonry, which are very sensitive to atmospheric agents, and tend to delaminate and crumble.

As continuous restoration and maintenance works are required, its complexity, size and characteristics, the Cathedral offers a significant sample of challenges and issues to which refer and is a suitable case study to implement the methodology proposed.

\section{THE SURVEY CAMPAIGN}

In the Parma Cathedral case, the goal was to obtain a global 3D model of the Cathedral that can be used for HBIM implementation and as the basis for new detailed local surveys or further analyses. This entails that the final model is, at the same time, manageable (for its usage in a BIM environment) and finely detailed in order to adequately document the architectural details. To reach this, the survey outputs have to be of manageable size but with the proper resolution for appreciating the embellishment.

The Cathedral is located in the historic centre of Parma and overlooks the Piazza Duomo square. Another square (Piazzale San Giovanni) is present in the south-east corner, while, on the remaining sides, the Cathedral is surrounded by narrow streets. Among the function of the HBIM model, particular importance has the representation of material degradation. To this aim, the realization of orthophotos of the external façades was mandatory and the possibility to associate them to the 3D model has been foreseen.

Restitution was planned for a nominal average scale of 1:50, reserving the 1:100 scale for less accessible areas and 1:20 for some peculiar details.

Integrated survey techniques, multi-resolution and scalability were identified as key elements to fulfil the above listed goals.

\subsection{Topographic survey}

A stable and georeferenced topographical network, to which refer all measures has been established. The station points of the topographical network were located all around and inside the cathedral. The network has been designed in order to:

- be stable and sufficiently redundant

- ensure a homogeneous coverage all around the cathedral

- support all survey campaigns of the Cathedral, including the crypt and matroneums.

In order to make the reference system stable and lasting, outdoor station points have been marked with steel nails while indoors, not to spoil the marble pavement, well defined floor features, such as edges or veins, were selected and monographed. Twenty-two stations were materialized, as shown in Figure 3, and surveyed.

The survey of the topographical network has been carried out twice: both with the Topcon Image Station IS2 total station and Leica C10 laser scanner, in order to achieve greater accuracy on the final adjustment, thanks to the redundancy and robustness of observations.

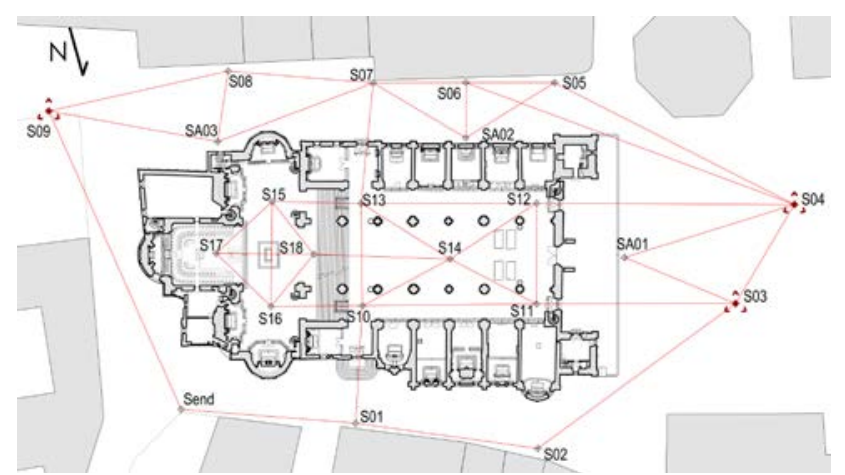

Figure 3_Topographical network of traverses.

In such networks, total station (TS) survey is mandatory. High TS angular and distance measure precisions assure accurate determination of the network points and the establishment of a rigid reference system. The laser scanner was used as a topographical instrument, measuring from each scan station all the network points signalized with targets. This method is commonly used for scan registration if targets positioned on the building surface or algorithm for registration of common scan areas are not used. Distance laser scanner observations have been exploited here not only for scan registration, but also to strengthen the global adjustment, reducing uncertainty and increasing reliability.

Total station and laser scanner observations were adjusted through rigorous least squares minimization with the software Calge (Forlani et al., 1986) separating horizontal and altimetric coordinates. The mean accuracy obtained for the local coordinates of station points was of ca. $2.1 \mathrm{~mm}$, which can be considered acceptable for most modelling and monitoring activities if very high precisions are not required.

The topographical network was georeferenced with a GPS survey of three vertices (vertices S03, S04 and S09), placed in the two squares at the opposite corners of the cathedral (Piazza Duomo and Piazzale S. Giovanni).

The GPS coordinates were obtained through 4 hours static session with respect to a station of the CORS (Continuous Operation Reference Station) network Netgeo about 9 km away and then transformed in a local Cartesian reference system with origin in the midpoint between the GPS stations.

\subsection{Laser scanner survey}

As far as the laser scanner is concerned, the Leica Geosystem C10 scan station was used. The survey was realized with a multi-resolution approach, so two different scan phases have been designed: a global survey and a detailed survey. The global survey aimed at generally document the cathedral, having a complete survey of its main volumes. For these reasons, 19 scans were performed taking advantages of the topographic network points.

The scans were acquired all around the Cathedral, in the nave, in the transept and in the choir. The scans were acquired with an average resolution of $6 \div 7 \mathrm{~mm}$ on the object. The scans carried out in the area of the presbytery (S15, S16, S17, S18) were instead acquired with a resolution of $2 \div 3 \mathrm{~mm}$ on the object, due to the high level of detail in the presbytery area.

The detail survey was designed to reach a high point cloud resolution, with an average distance between the points equal or less than $5 \mathrm{~mm}$.

TLS data were registered in Cyclone, which allows registering clouds on the basis of a known coordinate dataset and not just point cloud co-registration or target detection. 
The registration provided satisfying results, with an average residual of $2 \mathrm{~mm}$ and a standard deviation of $1 \mathrm{~mm}$, in accordance with the instrument nominal precision.

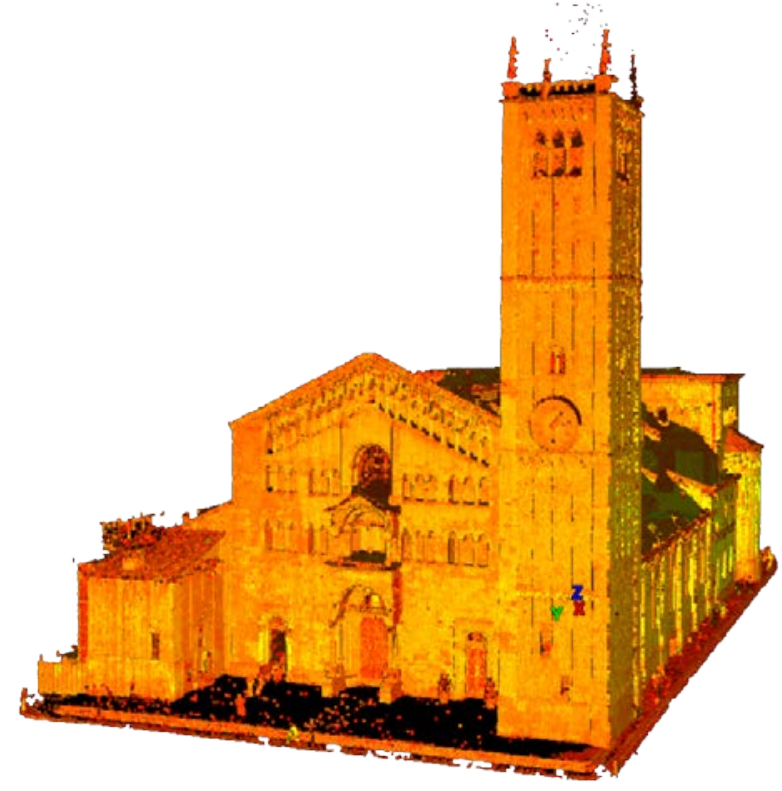

Figure 4_The complete point cloud after registration.

\subsection{Photogrammetric survey}

Although laser scanning is widely used in historical building surveys, where complex irregular objects require a full 3D description, limits in precision range, resolution and geometric and radiometric accuracy and/or portability might emerge.

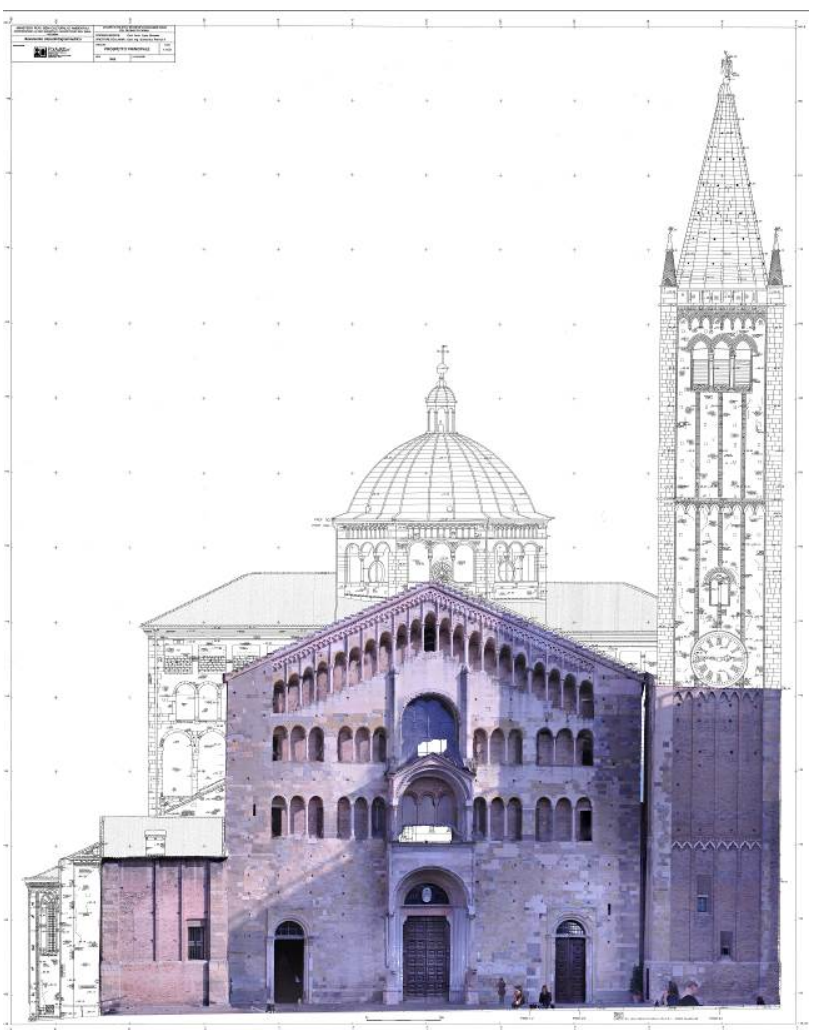

Figure 5_Orthophoto of the Cathedral main façade overlapped to the drawings of the photogrammetric survey made by FOART in 1989
In the Parma Cathedral survey, photogrammetry provides an essential integration to TLS, though image acquisition presents numerous difficulties: ground level images are affected by many occlusions and the narrow streets around the Cathedral dictate oblique imaging in order to frame the upper part of the façades, with large variations in image scale from the base to the top of the façade. This in turn cause a progressive decrease of accuracy and resolution from the lower to the upper parts.

An Unmanned Aerial System (UAS) would provide a much better imaging geometry and would be beneficial for detection of the areas not visible from the ground level, with reduction of occlusions and for the roofs survey.

However, at this time, the survey with the drone has not yet been possible for issues related to authorization to fly in the city centre. Therefore, for the moment, only images from ground have been taken, suitable to model the building up to the level of the lower eave (side chapels and apses).

A Nikon D3x (resolution 6048x4032 pixel, pixel size $6 \mu \mathrm{m}$ ) with $35 \mathrm{~mm}$ optics has been used. The site constraints (narrow streets, high façades with many depth changes) prevented using longer focal lengths; $35 \mathrm{~mm}$ can be considered a good compromise between the wide field of view requested, ground resolution and the reduction of optics distortion as well as other photographic issues (vignetting, chromatic aberration, etc.).

The photogrammetric block was designed to reach a precision adequate for 1:50 representation scale $(\sigma=1 \mathrm{~cm})$.

The image sequence consisted of 326 images that were oriented automatically using Agisoft Photoscan. High accuracy image orientation with a generic pair pre-selection modality has been chosen. To define the reference system of the restitution and orient absolutely the image block, 15 well-distributed Ground Control Points (GCP) were selected on natural features (e.g. edges, corner, surface discontinuities, etc.) since, for the moment, the Cathedral Fabbriceria did not granted permission the installation of permanent targets to the Cathedral walls.

The use of natural points makes collimation more difficult and point identification less precise. This is true despite a GSD of the order of $3 \mathrm{~mm}$, as the edges of architectural elements are always worn and corroded. For this reason, in order to improve the accuracy of the photogrammetric survey, using artificial targets is desirable. Therefore, in accordance with the drone survey campaign, the authorization for installation will be requested again.

At the end of the structure from motion procedure, with the same software package, the DSM of the exterior side of the Cathedral was obtained. In addition, the high-resolution orthophoto (GSD $3 \mathrm{~mm}$ ) were produced (Figure 5).

\subsection{Survey metadata}

The final accuracy of the model is influenced by both the quality of the data surveyed and the modelling operations carried out. For this reason, since the information system is based on the 3D model, for a correct use of the data obtained from it, it is important to certify its accuracy and reliability. Metadata on survey and modelling methods, on the accuracy obtained and on the correspondence of the model to reality, are a first instrument for monitoring data quality and the basis for a rigorous and scientific analysis of the object under investigation.

In addition, in complex surveying processes, documentation of the executed process becomes even more important to allow the entire chain to be reconstructed and the executed control/verification to be performed.

Therefore, a methodology to enter the quality of the survey in the database linked to the geometric model, and let the user to 


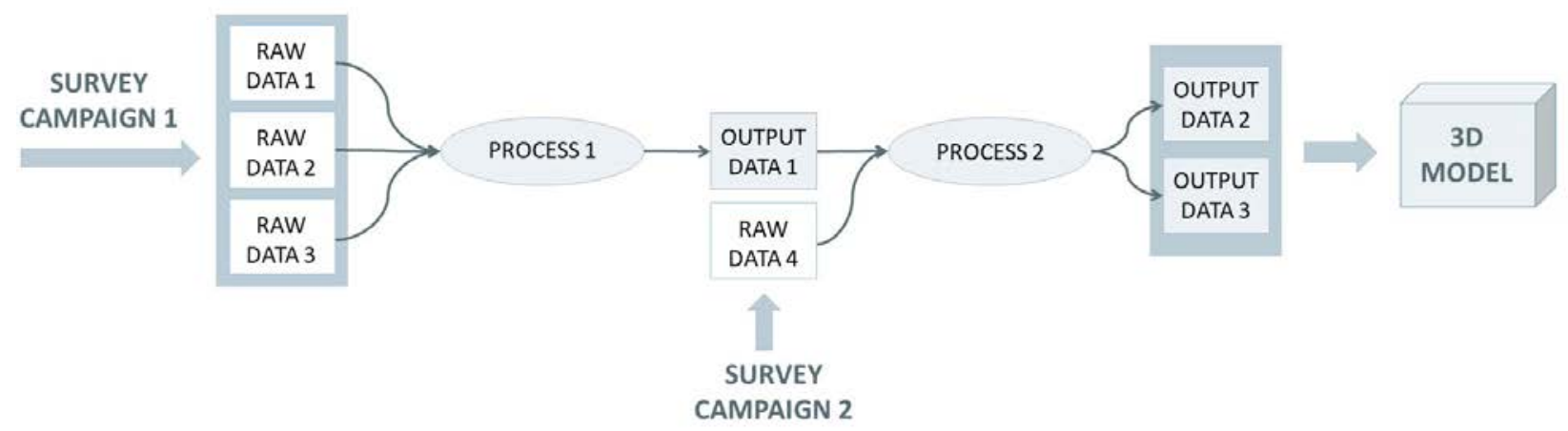

Figure 6_Schematic example of a survey process

verify at any time the correctness of the product he is working on, has been set up.

A database section was specifically structured to host data and metadata related to the survey, which would allow its description and documentation, in order to provide the user with a tool to control and keep track of the operations carried out.

The survey has been conceived as the sum of Survey Data and Processes. The data may be either the raw data or the processes output. Processes document the type of elaborations, with the associated input and output data.

The structure of the database makes it possible to link data and processes in a sequential way, in order to reconstruct the entire sequence of raw data, processes and processed data, from the initial data produced by the instrument to the output data used for modelling (Figure 6). Both with regard to data and processes, it is possible to associate descriptive metadata and the link to specific external reference files.

The data entry is possible through specific graphical user interfaces.

\section{THE MODELLING PHASE}

In the $\mathrm{CH}$ field, the modelling methodology is still an open question and copes with the difficulty to retrace the correct shape of the object (Barazzetti et al. 2015). Historical buildings are irregular and characterized by heterogeneous and complex shapes. In addition, the action of time causes damages and deformations on the architectural elements.

Mesh surfaces can represent complex objects that cannot be described by simple geometric rules but the final model is generally scarcely manageable and geometric operations, editing and semantic enrichment are difficult to perform.

On the other hand, parametric modelling allows easy semantic enrichment, speeds up the modelling phase, makes the model "intelligent" and adaptable to many specific cases, but entails object description with a finite number of parameters and rules. So the questions are: how can the model deviate from the real object shape? Do the benefits of such accurate model compensate for modelling efforts? Moreover, elements are often eroded by time and with obvious gaps. Their current conformation not only is different from any current geometric elements, but it does neither correspond to the original one. Therefore, conceptually, in order to be adherent to the present state, such objects have to be modelled as free form objects because each geometric approximation is arbitrary. But when does that make sense?

From the restoration's point of view, it would be great to have a $3 \mathrm{D}$ model correct in all its parts, reliable and compliant to the tolerance given by the scale of representation, from which to extract all the required elaborations. However, to date, the cost and the difficulties in realizing such accurate models are very high. Integration of different modelling techniques using mesh surfaces too could be a feasible solution, but cause interoperability problems (Tommasi et al., 2016)

In this case study, a hybrid solution that combines parametric models, direct modelling into BIM environment and meshes has been proposed, trying to overcome interoperability problems using links to external references. In this way, the HBIM is conceived as an archive, an information collector and a unique access point to different data.

Mesh modelling was applied to decorative elements that were linked as external files to BIM elements modelled using simple shapes with comparable volume.

Parametric modelling was performed for repetitive and geometrizable elements, but some parameters were defined as instance parameters in order to edit them locally on the model to allow a better correspondence with the point cloud.

In all other cases, combined techniques were used. First of all, the direct modelling of the elements by extracting 2D profiles from the point cloud and modelling through functions such as extrusion, blending, revolution and Boolean operations.

In addition, on some sample elements (walls, vaults, semidomes and floors), a test was performed in order to compare different modelling workflow and evaluate the better adherence to surveyed data. The test was realized in Revit environment and three different modelling strategies have been tested, in order to reach the highest level of accuracy, trying to preserve, as far as possible, the parametric feature of the objects.

Here, in particular, the test on a deformed wall is presented: non-linear development, out of plumb and deformations along the vertical development are considered.

The first tested mythology (A) (Figure 7) refers entirely to inplace modelling using only direct modelling tools. The point cloud representing the wall was sectioned with a horizontal plane at the base and at the top. The two closed profiles that define these two sections were then drawn. A blending operation allowed to create the wall starting from the base and top profiles.

The second implemented methodology (B) was to create a wall based on a surface, using the Revit function "Wall by face" that allows placing walls on non-horizontal faces of a mass instance or a generic model. Conversely from the previous case, here it is necessary to section the wall at different levels to reproduce more faithfully its conformation. Moreover, only one side of the wall (e.g. internal) is sectioned while the other will be modelled consequently. Based on the sections made, a surface or solid mass is created. On this surface, then, the parametric wall by face will be created. 

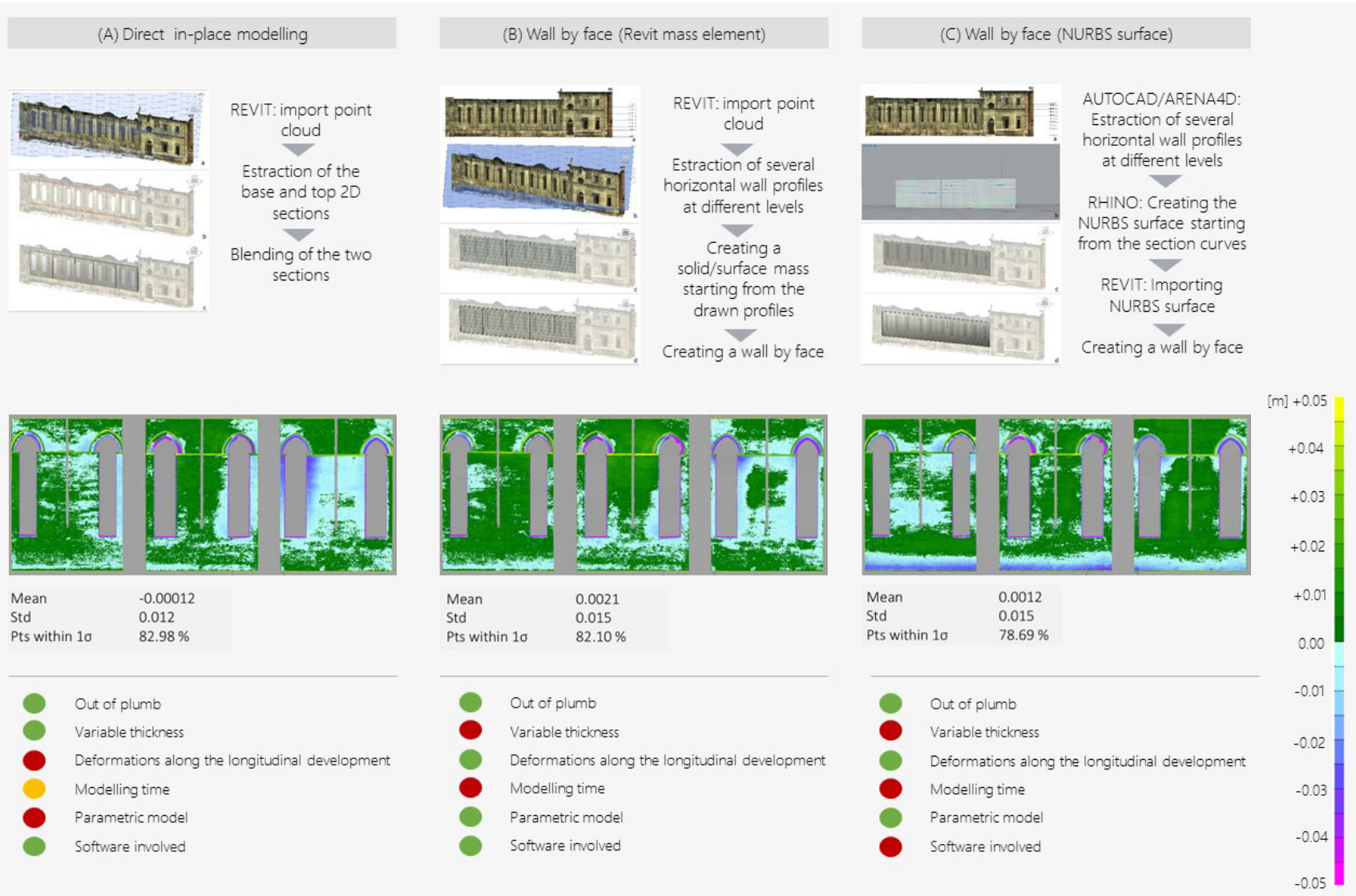

Figure 7_Summary and comparison of the three tested methodologies.

The third approach (C) is similar to the second one, but it differs in the first step. As in the previous case, this workflow leads to the creation of a wall by face, but starts from a NURBS surface. Creating a NURBS surface from the point cloud, using modelling software such as Rhinoceros (Rhinoceros 2018), could ensure a higher accuracy and a better adherence to reality. Nevertheless, it requires the use of software different from Revit and could cause interoperability problems.

The comparison (Figure 7) showed that the results from a metric point of view are more or less comparable. Other factors, in particular the need to create parametric or unique elements, modelling times and efforts, must therefore be taken into account.

\subsection{D and 3D mapping}

In historic buildings documentation, the surface mappings (referring at the same time to material, decay or damages) are an important requirement. They enrich the geometrical survey and give thematic information about the asset. Mappings are the basis for any restoration or conservation interventions that affect the façades of a building and are, therefore, one of the documents required by the superintendents when approving the projects. For this reason, considering a progressive use of the BIM for building conservation, it is mandatory to edit these documents directly into BIM.

Producing mappings in BIM environment is difficult. In fact, BIM software usually does not allow associating information to two-dimensional elements, such as polygons. A first response to this need is presented by (Chiabrando et al., 2017), producing 3D mapping directly on the building façade through specific adaptive components.
The methodology proposed here starts instead from orthophotos and is able to produce automatically the correspondent mapping on the 3D model.

A plug-in to Revit was implemented for:

- Associating the orthophoto to the element and displaying it in a floating window in Revit

- $\quad$ utilizing them as a basic tool for 2D mapping

- Automatic 3D modelling of the correspondent elements starting from the $2 \mathrm{D}$ polygons.

This tool has been designed to facilitate the tasks of restorers, who usually work with two-dimensional mapping of materials, degradation or interventions to do/already done. With the tool presented here, the aim was to provide a new way of working on 2D drawings, directly in the BIM environment, with additional potentials that can be assimilated to GIS: the polygons drawn on the orthophoto are not simple hatched areas but vector polygons with attributes and with corresponding 3D element in the BIM model.

Moreover, each orthophoto is spatially related to the element to

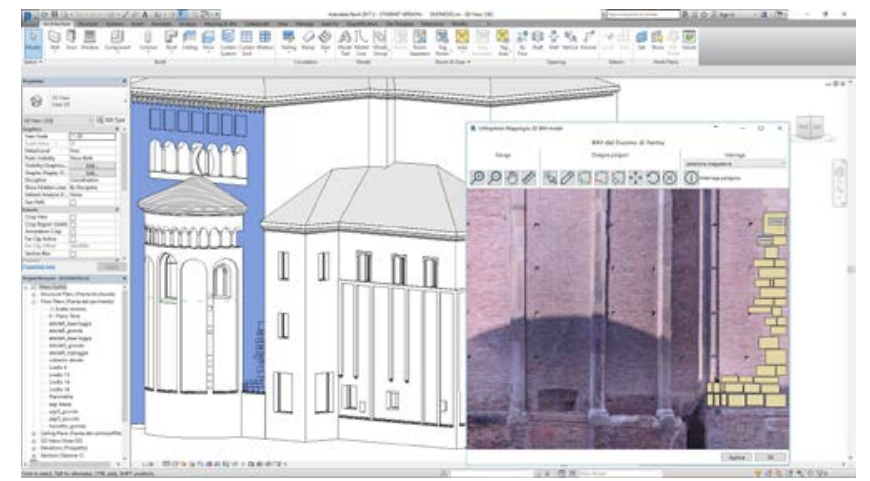

Figure 8_Example of mapping starting from orthophoto. 
which it is attached.

In this way, by using the "Create Parts" function of Revit, which divides the wall surface into delimited portions, the wall is automatically divided into parts corresponding to the 2D polygons drawn on the orthophoto. This also allows the user to get mappings in the three dimensions.

\subsection{Modelling metadata}

As for the survey, even for modelling, it is not yet adequately defined how certify and validate BIM model quality and accuracy.

To document the modelling process these data are required:

- A description of how the modelling has been done

- Data about the adherence of the model to the surveyed data (Level of Accuracy LOA)

- Data about the knowledge (geometric, structural and material) of the object (Level of Knowledge LK)

LOA refers to the five Levels of Accuracy (LOA10, LOA20, LOA30, LOA40, LOA50) as defined by the US Institute of Building Documentation (USIBD) and described in (USIBD 2016).

For the Level of Knowledge, instead, a specific reference standard that defines this parameter does not exist. Nevertheless, this concept can be compared with the Level of Knowledge (LK), provided by the Italian "Technical Standards for Construction” (Italian NTC 2009). Four different levels (LK0 Supposed, LK1 limited, LK2 Appropriate, LK3 Accurate) were introduced, divided by geometry, materials and structures, as described in the figure (Figure 9)

A section of the database was then structured to describe the modelling process (modelling technique, author, date, etc.) and to insert values related to the model's adherence to the surveyed data: LOA and LK.

This information can be entered through a specific interface and is associated to each single object modelled, since the global quality of the model could be, and is in the most cases, different from the local quality of the single items.

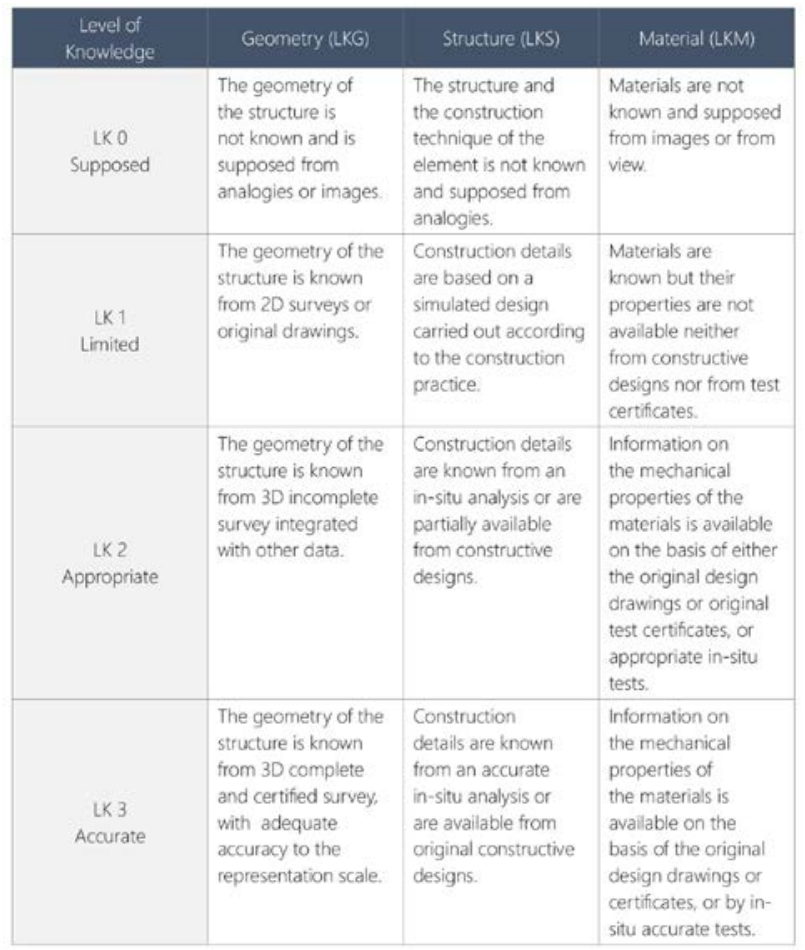

Figure 9_ Implemented Level Of Knowledge (LK) classification

\section{CONCLUSIONS}

The experimentation carried out in this research shows that the use of HBIM in the cultural heritage field is a good solution and a potential for more coordinated and efficient management and preservation. Nevertheless, a widespread application of HBIM system to cultural heritage buildings requires a large investment in terms of costs, training and processing times.

In particular, it is necessary to invest in technological development and scientific research to provide accurate and verifiable data, optimise and speed up surveying and modelling processes, overcome interoperability problems and create userfriendly systems.

As far as survey is concerned, nowadays acquisition techniques are well established and high precisions can be easily reached. In a BIM environment, current topics of research account instead the easy management of big data and how the survey outputs can be entered or linked to the BIM model.

In addition, for any BIM process applied to existing buildings the validation of the BIM model is fundamental: geometrical and semantic data has to be reliable and accurate enough to fulfil specific requirements and their reliability and accuracy should be properly documented by BIM authors. The final accuracy of the BIM model is affected by both the accuracy of the survey and the accuracy of the modelling and, in order to validate the quality of the BIM model, both survey and modelling phases should be certified.

In this work, a contribution is offered by proposing prototype tools that allow inserting all the metadata related to the survey and modelling, in order to certify the process and the final product. The tool allows the user to insert in the HBIM system all data about the modelling and survey phases (such as survey raw data, elaboration processes, information about the modelling strategies and accuracy) and associate them to each 3D element in the model.

As far as the modelling phase is concerned, this work addressed in particular two different topics: the integration in BIM environment of 2D and 3D modelling products and techniques and the evaluation of metric adherence between 3D model and surveyed data. W.r.t. the former topic, a Revit plug-in has been implemented to associate elements in the 3D model with the corresponding orthophoto. As in a GIS environment, the user can make mappings by drawing two-dimensional polygons directly on the orthophoto and the 3D element is automatically divided into parts corresponding to the $2 \mathrm{D}$ polygons drawn on the orthophoto.

In order to test modelling accuracy, hybrid solutions that combine parametric models, direct modelling into BIM environment and meshes have been tested and specific modelling workflows have been compared.

Nevertheless, the realization of accurate models, able to retrace the irregular shape of some historical architectural elements, presents still several problems and a solution is far from being reached. Modelling simplifies always the surveyed data so the model is inherently different, to some extent, from the real object. To overcome this limitation, whenever a faithful representation of the object cannot be ensured, HBIM should been conceived, in authors opinion, more as an archive, an information system and a unique access point to different data, in which all data (survey data, information, local mesh models etc.) can be entered, without expecting the 3D model to faithfully represent the reality. When this occurs is obviously strongly related on cost/time consideration and must be carefully evaluated in relation to the HBIM purpose. 


\section{ACKNOWLEDGE}

The Fabbriceria del Duomo di Parma assistance, in particular of Eng. Gualtiero Savazzini and Arch. Sauro Rossi, and the precious helpfulness of Stefano Volta are greatly acknowledged.

\section{REFERENCES}

Achille, C., Brumana, R., Fassi, F. \& Tuncer, H. (2007). Application of mixed technique for the 3D modelling of the noble floor of the Real Villa in Monza. International Archives of the Photogrammetry, Remote Sensing and Spatial Information Sciences, 36(5/C53).

Autodesk Revit - https://www.autodesk.it - Accessed 04/2018.

Barazzetti, L., Banfi, F., Brumana, R. \& Previtali, M. (2015). Creation of parametric BIM objects from point clouds using NURBS. The Photogrammetric Record, 30(152), pp. 339-362.

Bruno, N. (2018). From survey to analysis for Cultural Heritage management: a new proposal for database design in BIM. PhD Thesis, University of Parma, Italy.

Castagnetti, C., Dubbini, M., Ricci, P.C., Rivola, R., Giannini, M. \& Capra, A. (2017). Critical issues and key points from the survey to the creation of the historical building information model: the case of Santo Stefano Basilica. International Archives of the Photogrammetry, Remote Sensing and Spatial Information Sciences, 42 (5/W1), pp. 467-474.

Chiabrando, F., lo Turco, M. \& Rinaudo, F. (2017). Modeling of the decay in a HBIM starting from the 3D point clouds. A followed approach for cultural heritage knowledge. The International Archives of the Photogrammetry, Remote Sensing and Spatial Information Sciences, 42(2/W5), pp. 605-612.

Crespi, P., Franchi, A., Ronca, P., Giordano, N., Scamardo, M., Gusmeroli, G. \& Schiantarelli, G. (2015). From BIM to FEM: the analysis of an historical masonry building. In Mahdjoubi L., Brebbia C.A. \& Laing R. (editors), Building Information Modelling (BIM) in Design, Construction and Operations, Witpress, pp. 581-592.

De Luca, L., Bussayarat, C., Stefani, C., Véron, F. \& Florenzano, M. (2011). A semantic-based platform for the digital analysis of architectural heritage Computers \& Graphics. Volume 35, Issue 2, April 2011, Pages 227-241. Elsevier.

Dore, C., Murphy, M., McCarthy, S., Brechin, F., Casidy, C. \& Dirix, E. (2015). Structural simulations and conservation analysis - historic building information model (HBIM). International Archives of Photogrammetry, Remote Sensing and Spatial Information Sciences, 40(5/W4), pp. 351-357.

Eastman, C., Teicholz, P., Sacks, R. \& Liston, K. (2008). BIM Handbook - A Guide to Building Information Modeling for Owners, Managers, Designers, Engineers, and Contractors, John Wiley \& Sons, Inc.

Fai, S., Graham, K., Duckworth, T., Wood, N. \& Attar, R. (2011). Building Information Modelling and heritage documentation. Proceedings XXIII International CIPA Symposium, Prague, Czech Republic, September 12 - 16, 2011.
Fassi, F., Achille, C., Fregonese, L. Monti, C. (2010). Multiple data source for survey and modelling of very complex architecture. International Archives of Photogrammetry, Remote Sensing and Spatial Information Sciences, 38(5), pp. 234-239.

Fassi, F., Achille, C., Mandelli, A., Rechichi, F. \& Parri, S. (2015). A new idea of BIM system for visualization, web sharing and using huge complex 3D models for facility management. The International Archives of the Photogrammetry, Remote Sensing and Spatial Information Sciences, 40(5/W4), pp. 359-366.

Forlani G. \& Mussio L., 1986. Test on Joint adjustment of geodetic and photogrammetric data. International Archives of Photogrammetry and Remote Sensing, vol. XXVI, part 3.1, Rovaniemi, 1986, 237-251. issn 0256-1840.

Garagnani, S. \& Manferdini, A.M. (2013). Parametric accuracy: Building Information Modeling process applied to the cultural heritage preservation. International Archives of the Photogrammetry, Remote Sensing and Spatial Information Sciences, 40(5/W1), pp. 87-92.

Guidi, G., Remondino, F., Russo, M., Menna, F., Rizzi, A. \& Ercoli, S. (2009). A multi-resolution methodology for the 3D modeling of large and complex archaeological areas. International Journal of Architectural Computing, 7(1), pp. 39 55.

Italian NTC (2009), Circolare 2 febbraio 2009, n. 617 Istruzioni per l'applicazione delle "Nuove norme tecniche per le costruzioni” di cui al D.M. 14 gennaio 2008 - Cap. 8, Costruzioni esistenti.

Remondino, F. (2011). Heritage recording and 3D modeling with photogrammetry and 3D scanning. Remote Sensing, 3(6), pp. 1104-1138.

Rhinoceros - https://www.rhino3d.com/it/ - Accessed 04/2018.

Saygi, G. \& Remondino, F. (2013). Management of Architectural Heritage Information in BIM and GIS: State-ofthe-art and Future Perspectives. International Journal of Heritage in the Digital Era. 2 (4), pp. 695-713.

Stefani, C., De Luca, L., Veron, P. \& Florenzano, M. (2010). Time indeterminacy and spatio-temporal building transformations: an approach for architectural heritage understanding. International Journal for Interactive Design and Manufacturing (IJIDeM) 4(1), pp.61-74.

Tommasi, C., Achille, C. \& Fassi, F. (2016). From point cloud to BIM: a modelling challenge in the Cultural Heritage field. The International Archives of the Photogrammetry, Remote Sensing and Spatial Information Sciences, 41(B5), pp. 429-436.

USIBD (2016). Level of Accuracy (LOA) Specification Guide.

Volk, R., Stengel, J. \& Schultmann, (2014). Building Information Modeling (BIM) for existing buildings - Literature review and future needs. Automation in Construction 38, pp. 109-127. 